\title{
LA CIUDAD UNIVERSITARIA DE VALENCIA: UN LENTO Y CONTINUO PROCESO DE CONSTRUCCIÓN (1908-1969) ${ }^{1}$
}

\author{
David Sánchez Muñoz \\ Área de Conservación de Patrimonio Cultural. \\ Universitat de València
}

Resumen: A principios del siglo XX se empezó a construir la Ciudad Universitaria de Valencia en los terrenos del paseo de Valencia al Mar, actual avenida de Blasco Ibáñez. Sin embargo, el proceso se dilató durante años, dando como resultado un espacio singular. No existía hasta ahora un estudio exhaustivo de las circunstancias que propiciaron su origen, ni se había abordado con rigor la evolución cronológica de sus edificios. Para ello, ha sido necesario localizar numerosos expedientes, documentos y noticias de todo tipo, lo que ha hecho posible finalmente elaborar una narración cabal de aquello que pasó y de sus artífices.

Palabras clave: Ciudad Universitaria de Valencia, urbanismo, arquitectura, edificios, Historia.

The University City of Valencia: a slow and continuous construction process (1908-1969)

Abstract: The University of Valencia Campus started to be built at the beginning of the 20th century. Nevertheless, the building process lasted several years, and its result was a singular space. Till now, there wasn't a thorough study about the circumstances that contributed to this particular architectural project, and about the chronological evolution of these buildings. New documents and records have been found, in order to compose a consistent account of the facts.

Key words: City University of Valencia, urban planning, architecture, buildings, History.

\section{UNA BREVE Y NECESARIA INTRODUCCIÓN: LA CIUDAD UNIVERSITARIA DE MADRID. LA CONSECUCIÓN DE UN NUEVO Y MODERNO ESPACIO UNIVERSITARIO}

La Ciudad Universitaria de Madrid fue un claro referente para la de Valencia. Promovida por el rey Alfonso XIII, y proyectada por el arquitecto Modesto López Otero en 1928, cambió en España el paradigma de las viejas universidades europeas, construidas en el interior de las ciudades, a partir de un conjunto heterogéneo de casas; por cierto, modelo que había seguido también la universidad valenciana en sus inicios. La Ciudad Univer-

Data de recepció: 21 de juny de 2016 / Data d'acceptació: 29 de juliol de 2016.

${ }^{1}$ El año 1908 corresponde al proyecto de José Luis Oriol para las Facultades de Ciencias y Medicina, que inicia la construcción de la Ciudad Universitaria, aunque en aquel momento se formule como un proyecto aislado, dentro de las necesidades académicas de entonces. El año 1969 señala la fecha del proyecto de la Facultad de Economía, último de los edificios universitarios que fueron construidos en el tramo inicial del paseo de Valencia al Mar, actual avenida de Blasco Ibáñez. 
sitaria de Madrid, partió además del estudio de otras universidades extranjeras, a través de distintos viajes patrocinados por la Fundación Rockefeller. Entre los modelos visitados, se encontraban los grandes campus ingleses, que constituían núcleos uniformes y extensos. Sin embargo, fue el modelo norteamericano, que incluía además entre sus enseñanzas la práctica deportiva, el que finalmente adoptaría la nueva universidad madrileña. El aspecto paisajístico y urbanístico fue también determinante, extrayendo del modelo la necesidad de incorporar amplias zonas verdes como rasgo fundamental del campus universitario; siendo éste un elemento muy importante a tener en cuenta, junto con la necesidad de integrar, como parte de las instalaciones, las residencias para estudiantes. Mientras tanto, los sucesos políticos se suceden. La llegada de la Segunda República, con el exilio incluido del monarca promotor de la obra, no puso freno a la Ciudad Universitaria de Madrid, sino que la impulsó, abriéndose una etapa de esplendor en lo referente a su construcción. Al igual que en el periodo anterior, sigue dirigiendo la obra López Otero. Luego, la llegada de la guerra, con Sánchez Arcas como arquitecto responsable (Chías Navarro, 1983, vol. I, 139 y 1986, 151), y el cambio de paradigma del Régimen franquista que reformula el proyecto en función de sus intereses. De nuevo, López Otero, trabajador infatigable, retoma la dirección del proyecto, salvándolo de la ruina arquitectónica a la que había llegado al finalizar la guerra, aunque cediendo significativamente a unos planteamientos mucho más conservadores y monumentalistas, encaminados esta vez a ensalzar la victoria del bando vencedor, con el propósito de satisfacer ahora sus demandas propagandísticas. La figura clave de López Otero en Madrid es comparable, en cierta forma, al papel desempeñado en Valencia por el arquitecto Javier Goerlich. Ambos transitaron por distintos gobiernos con la intención firme de llevar a buen término el proyecto moderno de Ciudad Universitaria²

2 Aunque no es el objetivo principal de este artículo, debemos señalar algún texto de importancia sobre la construcción de las ciudades y de sus distintos espacios universitarios, en diferentes lugares y épocas, teniendo especial relevancia los europeos (destacando entre ellos los ingleses) y, sobre todo, los americanos. En este sentido, sigue siendo referencia ineludible la obra de Horacio Capel, La morfología de las ciudades, en concreto su volumen II, Aedes facere: técnica, cultura y clase social en la construcción de edificios, publicado por Ediciones del Serbal en 2005, que dedica amplios apartados a su estudio.

De la misma manera, la Ciudad Universitaria de Madrid es sin duda el modelo más próximo, encontrando una bibliografía muy variada, desde los escritos que López Otero realiza como reflexión y análisis de su obra, hasta los estudios específicos que, con mayor o menor extensión y profundidad, se han sucedido a lo largo de los últimos años. En este sentido, sin ser exhaustivos, cabe recoger las aportaciones de Pilar Chías Navarro, con su libro La Ciudad Universitaria de Madrid: génesis y realización, publicado por la Editorial de la Universidad Complutense en 1986, realizado a partir de su tesis doctoral La Ciudad Universitaria de Madrid: planeamiento y realización, defendida en la Universidad Politécnica de Madrid en 1983; o el ya posterior, 75 años de la Ciudad Universitaria de Madrid: memoria viva de un campus trascendental, de Pablo Campos Calvo-Sotelo, impreso en 2004 por la Editorial Complutense; y del mismo autor, pero más tarde y en relación a los diferentes modelos universitarios, España-Campus de Excelencia Internacional, publicado por el Ministerio de Educación en 2010, sin olvidar la publicación de su reconocida tesis doctoral, La universidad en España: historia, urbanismo y arquitectura, del año 2000, entre otras muchas aportaciones.

También debemos incluir algunas referencias coetáneas a los procesos de construcción del campus madrileño. Aquí cabe citar, sin entrar a valorar la calidad de los textos ni su intención ideológica, por ejemplo, la Ciudad Universitaria de Madrid: notas críticas, de Javier de Luque, publicado por la Imprenta Góngora en 1931; el monográfico dedicado a la Ciudad Universitaria de la Revista Nacional de Arquitectura, número 6 de 1941; o, el más tardío, La Ciudad Universitaria de Madrid, editado por la Junta de la Ciudad Universitaria en 1947. 


\section{CONSTRUIR UN NUEVO ESPACIO O LAS INERCIAS DE UN URBANISMO DEMOLEDOR}

El impulso de la Ciudad Universitaria de Valencia, en el actual campus de Blasco Ibáñez, vino determinado por el desarrollo de un proyecto urbanístico: el paseo de Valencia al Mar. La aspiración de unir la ciudad con el mar había sido una constante en el ideario programático de las reformas urbanísticas desde mediados del siglo XIX. En este sentido, el primero en darle forma fue Manuel Sorní Grau (1865), siendo Meseguer el que lo definió finalmente. Sin embargo, el proyecto había quedado en el olvido y sólo fue retomado con decisión algún tiempo después. Instalado el gobierno de la Segunda República en abril de 1931, el equipo municipal prepara algunos proyectos muy importantes que se detallan en magníficas perspectivas firmadas entre abril y septiembre del mismo año, lo que coincide con el periodo de gobierno del alcalde Agustín Trigo Mezquita. Entre las propuestas presentadas caben destacarse: la reforma de la plaza del Ayuntamiento (que adquiere su forma actual), la avenida del Oeste (sobre un anteproyecto anterior de Federico Aymamí firmado en 1906) ${ }^{3}$ y el paseo de Valencia al Mar ${ }^{4}$. Las dos últimas tenían mucho que ver con las corrientes más reaccionarias del urbanismo europeo decimonónico. Éste se caracterizó por incorporar a las ciudades grandes y rectas avenidas que se abrían paso por los maltrechos centros históricos de las anquilosadas urbes occidentales.

La avenida del Oeste partía de las propuestas radicales de Haussmann y la transformación moderna de París. Por entonces, otras reformas importantes fueron realizadas en las europeas Londres y Viena y, también, en las españolas Madrid y Barcelona. Mientras tanto, al otro lado del atlántico, se levantan imponentes rascacielos que asombran al mundo, siendo Nueva York paradigma de la ciudad cosmopolita que crece vigorosamente a lo alto, gracias a las potentes estructuras de acero.

Junto con la avenida del Oeste se lleva a cabo la reforma de la plaza del Ayuntamiento, con tonos regionales, barrocos y cierta monumentalidad, quizá excesiva para la Valencia de su tiempo. Por último, la propuesta del paseo de Valencia al Mar, que albergará la Ciudad Universitaria, se proyecta como una gran avenida que nace junto a los Viveros municipales, con la intención de que su recorrido terminara cerca del mar. Es importante señalar que este proyecto preservaba en su último tramo el actual barrio del Cabañal. Por lo tanto, la incidencia radical de esta gran vía cedía a postulados mucho más sensatos, mediante la conservación parcial de los Poblados Marítimos. El proyecto del paseo de Valencia al Mar tenía como precedentes inmediatos la Ciudad Lineal de Arturo Soria y el modelo británico de la Ciudad Jardín de Howard, referentes que, como en el caso de la reforma parisina, partían de los ideales urbanísticos de finales del siglo XIX, un tanto utópicos y bien intencionados, para construir ciudades más luminosas, limpias y amables,

3 Este importante y poco conocido anteproyecto se dio a conocer en: Amando Llopis-VTiM arqtes. y David Sánchez Muñoz, "La ciudad que se encontró Javier Goerlich. A propósito de algunos proyectos sobre Valencia y su Reforma interior (1855-1925)". En: València 1808-2015: La història continua... Valencia, Ed. Balandra, 2016, 81-116.

${ }^{4}$ El 1 de agosto de 1893, Gaceta de Madrid del día 5 del mismo mes y año, se declara de utilidad pública un camino paseo de Valencia al Mar que, partiendo de la plaza del Jardín del Real termine en Pueblo Nuevo del Mar. 
con el propósito burgués de una vida mejor. En este sentido el modelo debía integrar a toda clase social.

La propuesta de la avenida del Oeste y la reforma de la plaza del Ayuntamiento fueron firmadas por el arquitecto mayor Javier Goerlich mientras que el paseo de Valencia al Mar lo estaba por el arquitecto municipal José Pedrós. Las tres reformas fueron convenientemente difundidas para el conocimiento de la ciudadanía mediante la proyección en cines, en noviembre de 1931, de las perspectivas y vistas de los proyectos. Ahora ocupa la alcaldía Vicente Alfaro. En estas proyecciones, se incluían además algunos textos que explicaban brevemente las líneas básicas de las intervenciones urbanísticas que iban a ser realizadas. En relación al paseo de Valencia al Mar el texto decía lo siguiente:

Comprende una zona de terrenos de 300 metros de anchura con una longitud de 3.250 metros.

Empieza en la calle núm. 138 lindante con los Viveros Municipales y acaba en la calle de San Pedro del Cabañal, donde se bifurca en dos avenidas que llegan a la playa.

La urbanización de dicho paseo, consiste en una calzada central de cien metros, subdividida en dos avenidas de treinta metros de amplitud y un macizo central de cuarenta metros.

Las dos zonas laterales de cien metros cada una, se subdividen por una calle de doce metros en dos manzanas destinadas a la construcción.

En este paseo se está construyendo las Facultades de Medicina y Ciencias. En él se ha de emplazar la Ciudad Universitaria y además la Ciudad Jardín compuesta de casas baratas y económicas en forma de Chalets.

En la realización de este proyecto podrán hallar trabajo más de 500 obreros durante dos años ${ }^{5}$.

\section{UN PASEO PARA VALENCIA. UN LUGAR PARA EL CONOCIMIENTO: LA CIUDAD UNIVERSITARIA}

En octubre de 1906 se convocó, a través del Ministerio de Instrucción Pública y Bellas Artes, un Concurso de proyectos de un edificio destinado a las Facultades de Ciencias y Medicina con su hospital clínico de la Universidad de Valencia ${ }^{6}$. A este certamen se presentaron sólo dos propuestas, la del arquitecto Ferriol, que no fue premiada, y la del arquitecto Oriol (hombre de trayectoria singular), que finalmente ganaría.

En el paseo de Valencia al Mar se iban a levantar las nuevas Facultades de Ciencias y Medicina, según proyecto inicial de José Luis Oriol de $1908^{7}$ que luego será transformado.

5 El texto está extraído de la placa de linterna utilizada en los cines, propiedad de Carlos Viñes Goerlich, sobrino del arquitecto Goerlich y colaborador suyo durante años. De la imagen que acompañó al texto, con el título Vista aérea de la ciudad jardín en el paseo de Valencia al Mar, también se conserva la placa de linterna, no así el dibujo original que no ha sido encontrado todavía. Asimismo, la imagen fue publicada en la revista Blanco y Negro, el 9 de octubre de 1932, como parte del artículo "Del ayer al mañana", firmado por Almela y Vives.

6 AUV. Archivo General, caja 342/6. Publicado en la Gaceta de Madrid el 17 de octubre de 1906.

7 El proyecto completo de las Facultades de Medicina y Ciencias del arquitecto Oriol fue publicado por entregas en la revista quincenal La Construcción Moderna, números: 9 (15 de mayo de 1913, 133-140), 10 (30 de mayo de 1913, 145-151), 11 (15 de junio de 1913, 163-167), 12 (30 de junio de 1913, 178-182), 13 
Éste incluía, además de las dos facultades, la construcción de un Hospital Clínico. La posibilidad de contar con un nuevo edificio partió de las reiteradas exigencias que se hacían desde la Facultad de Medicina al Ministerio de Fomento. Los sucesivos decanos habían pedido además mejores medios para la enseñanza. Sin embargo, será Amalio Gimeno (antiguo alumno y profesor de la universidad valenciana), quien realice desde Madrid, como senador por la Universidad de Valencia, las pesquisas necesarias para su construcción; siendo además decisiva la adquisición de los solares por parte de la Diputación y el Ayuntamiento de Valencia (Gómez, 1915, 210-212). Así pues, la primera piedra de la Facultad de Ciencias y Medicina (que inició la Ciudad Universitaria de Valencia) fue colocada, en presencia de numerosas autoridades, entre ellas Amalio Gimeno, el 19 de diciembre de 19098. Sin embargo, y a pesar de este empuje inicial, las obras se paralizaron durante años.

Mientras tanto, un edificio singular para Feria Muestrario se levantará también en esta avenida. El proyecto había sido redactado en 1918 por los arquitectos Demetrio Ribes, Francisco Mora y Javier Goerlich, siendo utilizado por primera vez para la $5^{\text {a }}$ edición, entre los días 10 y 31 de mayo de 1922. En esta fecha sólo estaba terminada una parte del recinto ferial. Lo cierto es que el edificio no se construyó siguiendo un proyecto director homogéneo, ni tampoco se respetó el proyecto original. Sus dependencias sufrirán los inconvenientes de una obra en continua construcción, a la que se añadían puntualmente nuevos pabellones y espacios. La necesidad de construir posteriormente un edificio más moderno y capaz para la Feria Muestrario, hizo olvidar al antiguo edificio de paseo al Mar. No obstante, se intentarán buscar soluciones para el aprovechamiento de sus locales. Es así como al inicio de la década de los cincuenta del siglo XX, y ante la falta todavía de construcciones universitarias, se piense en utilizar parte de sus instalaciones para albergar las Facultades de Derecho y Filosofía y Letras, aunque finalmente no fueron utilizadas. En 1969 se llevó a cabo por última vez, en el recinto ferial de paseo Valencia al Mar, la 47 Feria Muestrario Internacional (celebrada del 4 al 19 de mayo) ya que el nuevo edificio de Benimàmet, donde iba a celebrarse a partir de ahora, estaba prácticamente terminado.

En los años 30 del siglo XX y a partir del impulso en la construcción del paseo, se levantan algunas casas que seguían el modelo de Ciudad Jardín, tal y como marcaba el proyecto presentado por Pedrós. Las primeras viviendas construidas por Enrique Viedma para la Asociación Valenciana de Prensa, las conocidas como "chalets de los periodistas", fueron proyectadas en 1931, con dos manzanas junto a la avenida, cerca de la Facultad de Ciencias, hoy Rectorado, entre la actual avenida de Blasco Ibáñez y calles Jaime Roig, Juan Martorell y Cavanilles, junto con la de Bernat y Baldoví que sirve de separación entre manzanas, y otro grupo más al lado opuesto del paseo, entre la actual avenida de Blasco Ibáñez y calles Periodista Badía, Doctor Moliner y Profesor doctor Severo Ochoa. De esta tercera manzana solo queda en pie una de las viviendas, la situada en la avenida Blasco Ibáñez, 16. A espaldas de éstas, entre las actuales calles Periodista Badía, Artes Gráficas, Doctor Moliner y Profesor doctor Severo Ochoa, fue realizado otro grupo, esta vez para la

(15 de julio de 1913, 201-206), 14 (30 de julio de 1913, 217-222), 15 (15 de agosto de 1913, 235-240), 17 (15 de septiembre de 1913, 270-272), 19 (15 de octubre de 1913, 299-302).

${ }^{8}$ La noticia aparece recogida en el diario ABC, 20 de diciembre de 1909, 11; La Correspondencia de España, 20 de diciembre de 1909, 4; también en el número 1461 de La Ilustración Artística, 27 de diciembre de 1909, 6 . 


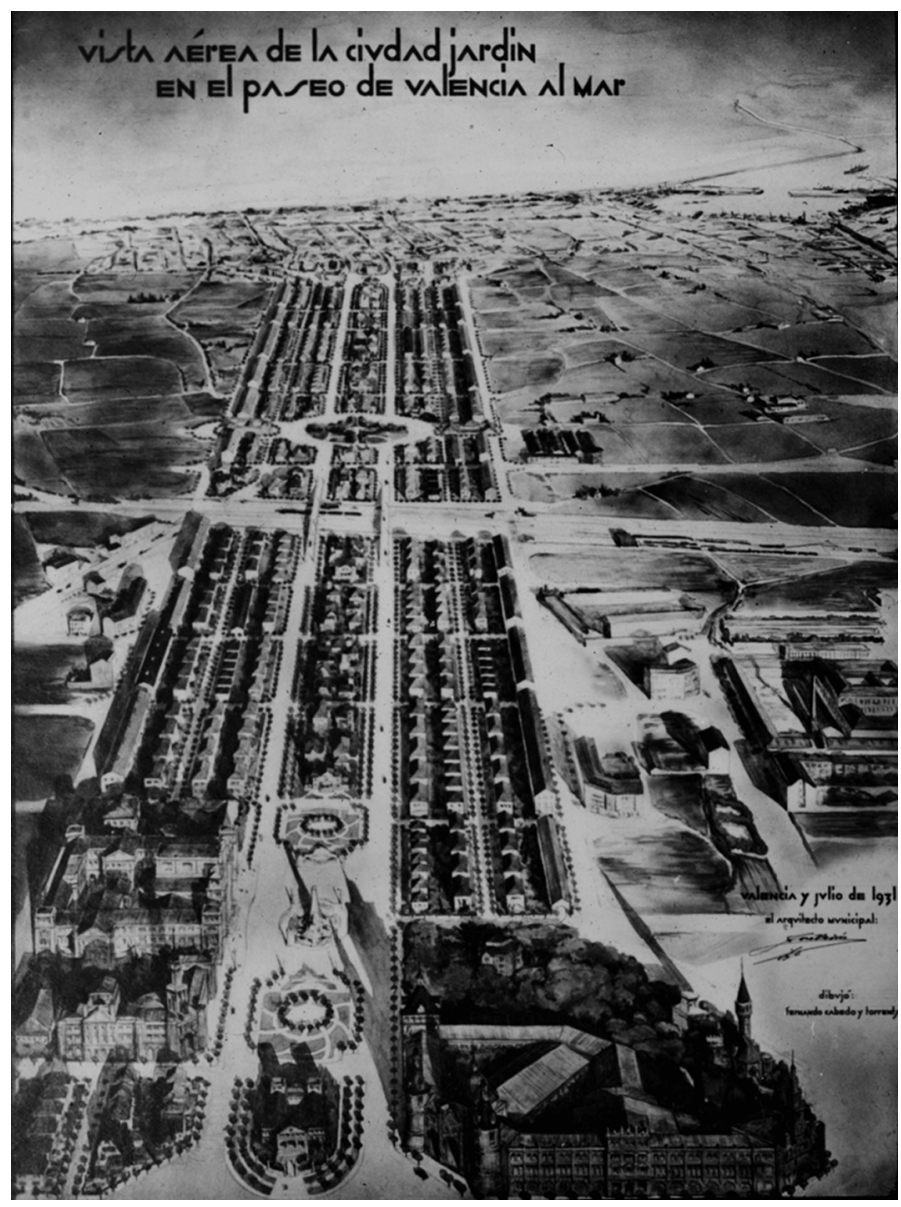

Vista áerea de la Ciudad Jardín en el paseo de Valencia al Mar. José Pedrós, julio de 1931. Colección Carlos Viñes Goerlich.

Cooperativa de Artes Gráficas, con proyecto de Emilio Artal de 1932, siendo demolido años después. Los grupos de viviendas de la Cooperativa de Casas Baratas de la Asociación de la Prensa Valenciana, y de la Cooperativa de Casas Baratas de Artes Gráficas, fueron construidos al amparo de la Ley de Casas Baratas de 1911 y, aunque muy interesantes, son ejemplos del modelo fracasado de Ciudad Jardín que se intentó para Valencia.

Mientras tanto, la Universidad valenciana se encontraba en situación de crisis, con pocos medios y numerosas huelgas estudiantiles que frenaban o paralizaban el correcto desarrollo de los estudios. En este contexto, como señala la interesante monografía sobre el rector Mariano Gómez escrita por Pascual Marzal (Marzal, 2009), se plantean algunas soluciones. La Facultad de Derecho, muy castigada por estas huelgas y en previsión de otras nuevas, acude al rector de entonces Rafael Pastor González, autorizándose la creación de un Consejo de Disciplina. En junta celebrada el 13 de diciembre de 1920 se leyó, según 
cuenta Pascual Marzal (Marzal, 2009, 79), el dictamen elaborado por una comisión que contaba entre sus miembros con Mariano Gómez (posterior rector de la Universidad), y los catedráticos Jordana, Zumalacárregui (que también será rector), Ros y Salom, respecto a las medidas de aplicación inmediata cuya adopción es conveniente y legalmente posible para evitar y, en su caso, corregir las faltas colectivas de asistencia que reiteradamente se producen en esta universidad. Proponiendo la necesidad de reformar las instalaciones universitarias y, con urgencia, las salas de lectura y trabajo, así como construirse una residencia de estudiantes; fomentar los ejercicios prácticos en todas las cátedras, también las excursiones y los deportes, los repasos y exámenes trimestrales; y conseguir la correcta identificación del alumnado con la creación de un fichero y un carné escolar.

En años siguientes tendrá continuación la idea de una Residencia de Estudiantes y Campo de Deportes, como lo demuestra el acta del Consejo Universitario del Patronato, de 31 de octubre de 1930, cuando es rector de la Universidad valenciana José Mª Zumalacárregui, en la que se señala: Se trató de la adquisición por compra de local para residencia de estudiantes y campo de deportes como medio de conseguir la mayor compenetración entre Profesores y alumnos y dar solución definitiva a los problemas de la actualidad, latente y palpitante. Intervinieron los Dres. López, Gómez, Cabrera, Castell y Rector, acordándose por unanimidad: $1^{\circ}$ ratificar el nombramiento de la ponencia ya designada a este efecto y que se halla compuesta por los Dres. Vicerrector Dr. Gascó y Dres. Gómez, Castell, cuyas gestiones hasta la fecha explicó el miembro de esta Dr. Castell, y la cual presentará planos, proyectos, esquemas, bases, etc. y $2^{a}$ solicitar la propaganda y colaboración de los estudiantes para estos fines ${ }^{9}$. No se realizó, pero se integrará en la Universidad un colegio gestionado por los dominicos, cuya primera piedra había sido colocada por Primo de Rivera el 28 de julio de 1926. Este edificio, según cuenta la prensa de la época, iba a estar destinado inicialmente a Colegio de Estudios Universitarios y residencia para estudiantes pobres ${ }^{10}$. No obstante, será Mariano Gómez el que insista finalmente en la construcción de una residencia de estudiantes propia de la Universidad (Sánchez Muñoz, 2016); entendiéndola como elemento fundamental en la organización y cohesión de la vida universitaria.

La llegada de la Segunda República propició el nombramiento de Mariano Gómez González como rector de la Universidad el 18 de abril de 1931, figura que iba a impulsar decididamente la construcción de un espacio universitario propio, situado en el paseo de Valencia al Mar, junto a las Facultades de Ciencias y Medicina. De hecho, en Junta de Gobierno, en sesión celebrada el día 23 de septiembre de 1931, se dirá: Insistió el Sr. Rector en sus puntos de vista sobre ese particular, haciendo notar que el Ayuntamiento está vendiendo terreno a 47 céntimos palmo y demostrando con otras diversas razones la conveniencia de aprovechar la coyuntura que en la actualidad se presenta para adquirir solares con bastante economía. Alentó a la Junta para comprar cuantas hanegadas se pueda en lugar continuo a las nuevas Facultades de Medicina y Ciencias, bien directamente de los propietarios si son módicos en sus precios, ora mediante expropiación forzosa por causa de utilidad pública. El Arquitecto Sr. Fungairiño posee planos y proyectos de terrenos y está dispuesto a explicarlos sobre el terreno, ofrecimiento que fue aceptado en el acto por la Junta y resolviendo trasladarse esta misma tarde con dicho Sr. a reconocerlos ${ }^{11}$.

\footnotetext{
9 AUV. Archivo General, Libro n ${ }^{\circ} 2518$, f. 4r-5v.

10 Nota de prensa recogida en $A B C, 29$ de julio de 1926, 14.

11 AUV. Archivo General, Libro n ${ }^{\circ} 2518$, f. 23r-24r.
} 


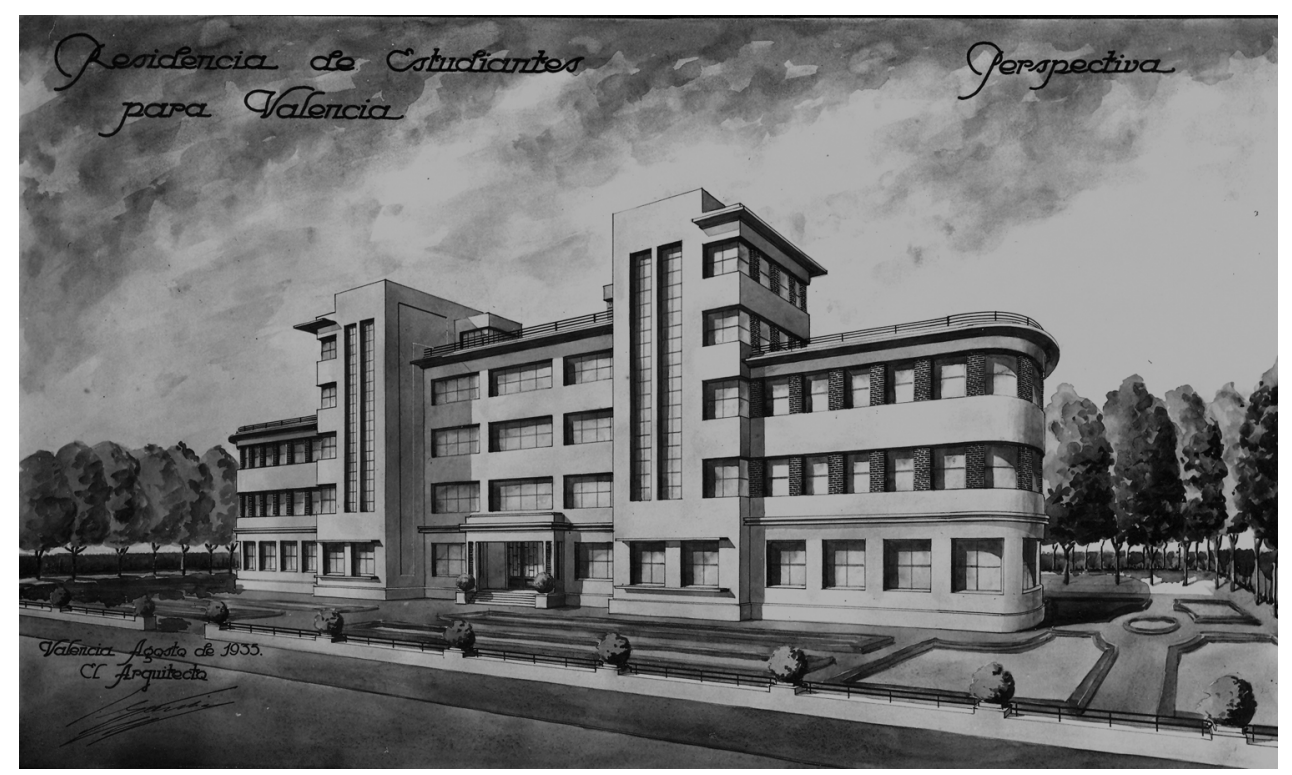

Residencia de Estudiantes para Valencia. Javier Goerlich, agosto 1935.

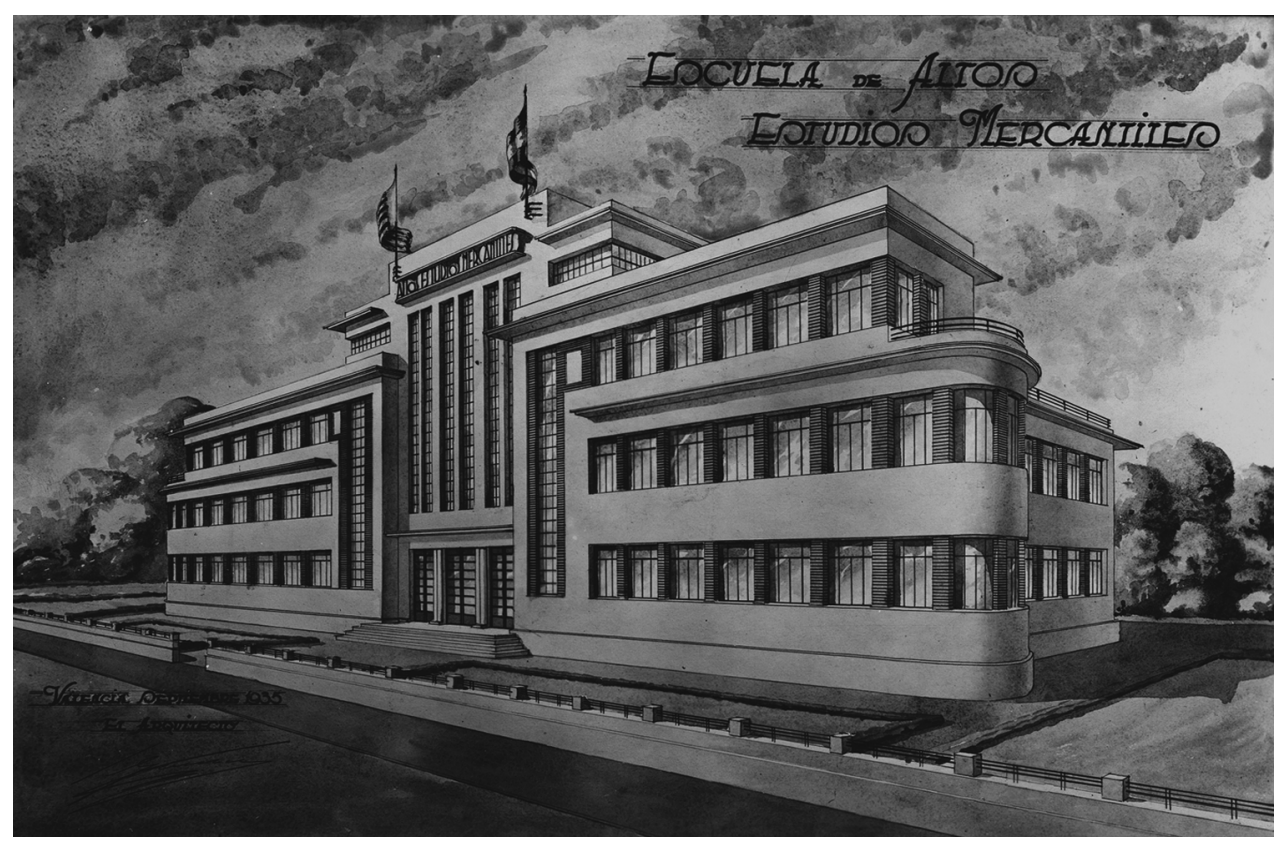

Escuela de Altos Estudios Mercantiles. Javier Goerlich, agosto 1935. 
El rector Gómez González pensó en dotar a la Universidad de unos mejores servicios e instalaciones, siendo recogidos por la prensa de entonces sus intereses: Espíritu ampliamente liberal y democrático, está dispuesto a estar en continuo contacto con los escolares, y viene animado de los mejores deseos de convertir en realidad lo que hasta ahora fueron sueños; tales son la creación de un Patronato de Cultura, de un barrio universitario junto adonde se está edificando la nueva Facultad de Medicina, en el que piensa instalar un gran campo de deportes; el nuevo Instituto, la Normal de Maestros y Maestras y la residencia universitaria; habiendo concebido la idea de que se municipalice el Jardín de Monforte para convertirlo en un museo de arte ${ }^{12}$. En este contexto, y en relación con la Residencia de Estudiantes, debe entenderse lo hablado en la Junta de Gobierno de la Universidad en sesión celebrada el día 17 de junio de 1931 a las 5 de la tarde. En esta reunión, presidida por el rector Mariano Gómez González, se habló de la ampliación de la Facultad de Ciencias y otros servicios de la Universidad (por entonces y aún en su sede histórica), mediante la compra de una casa situada en plaza del Patriarca junto al edificio universitario. Sin embargo, tema de mayor enjundia era la adquisición de nuevos solares para la construcción de una Residencia de Estudiantes junto a la Facultad de Medicina. Quedando reflejado en el acta que: El Sr. Presidente, aludiendo al acuerdo de esta Junta fecha 3 de abril de 1930 por el que fue designada una ponencia encargada de gestionar la compra de terrenos para emplazamiento de residencia de estudiantes, manifestó que sería muy conveniente aprovechar la ocasión que hoy se presenta de comprar a un precio relativamente económico una importante extensión de terrenos anejos a la nueva Facultad de Medicina en la zona del ensanche de esta capital, toda vez que más adelante, a juzgar por la depreciación que sufre nuestra moneda y el aumento de valor de los solares el mismo terreno quizá suponga un gasto mucho más elevado, pudiendo invertirse en esto el capital acumulado en el Patronato universitario para Colegios mayores ${ }^{13}$. Acordándose por unanimidad trasladar al Claustro esta iniciativa, proponiendo su autorización. Como vemos, la construcción de la Residencia de Estudiantes estuvo presente desde bien pronto.

Junto a la Residencia de Estudiantes, de vital importancia en el devenir universitario, se encontraba otro problema no menor. La Escuela Normal necesitaba también de nuevos locales, sus instalaciones precarias habían sido objeto de preocupación de tal forma que, el ministro de Instrucción Pública, Marcelino Domingo Sanjuán, y el director de Primera Enseñanza, Rodolfo Llopis Ferrándiz, hablarán sobre este asunto tan fundamental, obteniendo el segundo el apoyo de ministro para solucionar con prontitud el problema de la Normal. De tal forma que, el 22 de noviembre de 1931, Rodolfo Llopis visitó Valencia para impartir en el Teatro Apolo la conferencia "El momento pedagógico". Durante su estancia en la capital valentina se reunirá (entre otros) con el alcalde Alfaro y el rector de la Universidad Mariano Gómez, con el propósito de hablar sobre los nuevos edificios universitarios, siendo la Escuela Normal, que se pensaba construir por entonces en el paseo de Valencia al Mar, objeto principal de la conversación (Ruiz, 1993, 80-88) ${ }^{14}$. Al mismo tiempo expusieron el interés de llevar a cabo en estos terrenos la construcción de otros edificios universitarios, entre ellos la Residencia de Estudiantes o el Instituto-Escuela. Sin embargo, las propuestas concretas de los nuevos centros académicos parecían no llegar.

12 El Mercantil Valenciano, 19 de abril de 1931, 3. Citado por P. Marzal Rodríguez, 2009, 91.

13 AUV. Archivo General, Libro n ${ }^{\circ}$ 2518, f. 53r-53v. Citado por P. Marzal Rodríguez, 2009, 91.

14 La noticia fue publicada en El Mercantil Valenciano, el 24 de noviembre de 1931, 3. 
Además, la falta de sintonía entre el rector Mariano Gómez y el arquitecto de la Universidad, Javier Goerlich, era algo más que evidente. Es cierto, como señala Pascual Marzal (Marzal, 2009, 96-97), que esta falta de entendimiento pudiera venir de antes, posiblemente a raíz de las discrepancias surgidas en 1927 durante el concurso para nueva sede del Ateneo de Valencia, siendo entonces presidente de dicha institución el ahora rector. Sin embargo, parece más probable que Goerlich desatendiera, o pospusiera, el asunto universitario por otra razón. Desde finales de la década de los años veinte, y primeros años de la década de los treinta del siglo XX, el arquitecto se centró en la construcción de la plaza del Ayuntamiento y sus alrededores (Sánchez, 2014b, 86-88), una obra faraónica para entonces, realizada en muy pocos años, y que a buen seguro requirió de todos sus esfuerzos. De cualquier forma, Mariano Gómez transmitió sus quejas, llegando a solicitar, a la mayor brevedad posible, la destitución de este arquitecto, promoviendo para el puesto al también arquitecto Alfonso Fungairiño Nebot. Las dos cartas remitidas a Madrid con fecha de 17 de agosto de 1931, tenían como destinatarios al entonces ministro de Educación Marcelino Domingo y a Pedro Muguruza, un arquitecto importante y de prestigio, con reconocido peso en el ámbito nacional. Por su evidente interés transcribimos las mismas:

Carta del 17 de agosto de 1931, remitida al ministro de Instrucción Pública y Bellas Artes, Marcelino Domingo ${ }^{15}$.

Mi querido amigo e ilustre Jefe: Con esta misma fecha le remito una comunicación solicitando se sirva decretar el cese del Arquitecto de esta Universidad Sr. Goerlich y el nombramiento en sustitución del mismo del Arquitecto D. Alfonso Fungairiño, de cuya competencia y juventud espero satisfactoria y pronta subsanación de las perturbaciones que nos está originando el abandono de aquél. Recordará Ud., que en nuestra última entrevista le informé del caso, al cual tuvo Ud. la bondad de ofrecerme poner el adecuado remedio con la sustitución que entonces le pedí y ahora reitero, con tanto más motivo cuando que no veo otra solución que ponga término al actual lamentable estado de cosas.

Urge mucho que el nombramiento se haga cuanto antes con objeto de aprovechar estas vacaciones para hacer lo más indispensable. Para algo de ello cuento ya con una subvención de la Diputación y para otras cosas espero que no ha de faltar lo necesario. Si el nombramiento del nuevo Arquitecto viene pronto, todavía será posible que coincida con la apertura del nuevo Curso la inauguración de la Biblioteca, de dos Laboratorios y tal vez alguna otra de las mejoras más deseadas e indispensables.

Anticipándome las más expresivas gracias, se reitera a sus ordenes affm ${ }^{\circ}$. buen amigo y admirador.

Carta del 17 de agosto de 1931, remitida a Pedro Muguruza ${ }^{16}$.

Mi querido amigo: En mi último viaje a Madrid intenté verle, pero no tuve la suerte de encontrarle. Como he de volver pronto, entonces insistiré para no privarme de esa satisfacción, pues bien sabe Ud. el vivo afecto que le profeso y el grato recuerdo que siempre conservo de Ud.

\footnotetext{
${ }^{15}$ Documento facilitado por Irene Manclús, directora del Arxiu Històric de la Universitat de València. AUV. Archivo General, caja 919. Citado por P. Marzal Rodríguez, 2009, 92.

16 Documento facilitado por Irene Manclús, directora del Arxiu Històric de la Universitat de València. AUV. Archivo General, caja 919.
} 
Quería haberle hablado del mismo asunto de que ya le informó el amigo Fungairiño, o sea, de su nombramiento de Arquitecto de esta Universidad en sustitución de Goerlich. Conoce también el caso Marcelino Domingo, que me ofreció decretar el cese de Goerlich y el nombramiento de Fungairiño. Pero esto exige una tramitación que yo desearía se hiciera con la mayor diligencia posible. A tal objeto he cursado hoy al Ministerio una comunicación, de la que le remito copia y carta particular insistiendo en la necesidad de que haga cuanto antes lo que en aquella le pido. Me dijeron en el Ministerio que en ello ha de intervenir la Junta facultativa de Construcciones civiles, cuyo Secretario es el Arquitecto D. Manuel Zabala. Yo le agradecería a Ud. muchísimo que interpusiera su valiosa influencia para que la efectividad del deseo del Ministro y mío no se demore por dificultades burocráticas de tramitación, a las que tanto temo.

Algunos meses más tarde, la idea de construir nuevos edificios para la Universidad seguía presente. Es así como en Junta de Gobierno, celebrada el 9 de marzo de 1932, se presenta un presupuesto extraordinario para el ejercicio 1931-32, en el que se prevén los siguientes gastos:

I. Adquisición de terrenos para futuras ampliaciones de las Facultades de Medicina y Ciencias, Residencia de estudiantes y Campo de deportes de la Universidad.

$200.000,00$

$50.000,00$

$40.000,00$

$40.000,00$

$40.000,00$

$50.000,00$

$40.000,00$

$25.000,00$

$485.000,00^{17}$

El 4 de diciembre de 1931 se crea finalmente en Valencia mediante Decreto (Gaceta de Madrid del 6 del mismo mes y año) el Patronato de Cultura que tendrá como presidente y vicepresidente al rector y vicerrector de la Universidad de Valencia. Este organismo iba a propiciar la solución temporal de dos temas importantes: el del Instituto-Escuela y el de las Normales. En marzo de 1932 los acontecimientos se suceden vertiginosamente. El día 2 (Gaceta de Madrid de 6 de marzo de 1932) se crea en el incautado Colegio jesuita de San José un Instituto-Escuela que seguirá al de Madrid, cuyo inicio por Real Decreto databa de 10 de mayo de 1918. El mismo día, 2 de marzo de 1932, se dispone mediante Orden que, parte de los locales del Colegio de San José sean cedidos temporalmente para el funcionamiento inmediato de las Escuelas Normales. Sólo algunos días después, el 9 de marzo de 1932, comienzan las clases de las Normales en el citado colegio. Al mismo tiempo, la prensa local anuncia la salida del rector Mariano Gómez por su nombramiento como magistrado en Madrid: Ayer tarde recibimos la grata noticia de que el actual rector de nuestra Universidad don Mariano Gómez González había sido nombrado presidente de la Sala sexta (Guerra y Marina) del Tribunal Supremo. Y continúa: Con tal motivo don Ma-

17 AUV. Archivo General, Libro nº 2518, f. 37r-38v. Publicado también en: Mancebo, 1994, 124. 
riano Gómez tendrá que renunciar al rectorado de nuestra Universidad y al cargo de consejero de Estado. Mientras que en otro párrafo del mismo texto se dice: Su paso por el rectorado no podrá ser olvidado, pues sus actividades quedaron plasmadas en las reformas hechas en la Biblioteca Provincial y Paraninfo, así como también al crear el Patronato de Cultura y dar solución al problema de las Normales ${ }^{18}$. Quizá, el nombramiento de Mariano Gómez como magistrado en Madrid tuvo como consecuencia que finalmente Goerlich no fuera sustituido por Fungairiño, dándose la circunstancia de que estos dos arquitectos colaboraron en 1932 como autores de uno de los edificios más relevantes y brillantes del racionalismo valenciano: el Club Náutico. Javier Goerlich conservó durante muchos años más el puesto de arquitecto responsable de las obras universitarias.

Después, el terrible incendio del edificio histórico de la Universidad el 12 de mayo de 1932 afectó gravemente a la Facultad de Ciencias y al observatorio astronómico que allí se encontraban, lo que favoreció que las obras de las nuevas facultades de Ciencias y Medicina se reemprendieran. Esta circunstancia quedó presente en la Junta de Gobierno de 23 de mayo de 1932, presidida por el rector de entonces, el recién nombrado Juan Peset Aleixandre, en la que se dirá: Seguidamente el Sr. Rector dio cuenta de sus gestiones y del empeño del Gobierno de la República en auxiliar a la Universidad para la restauración de la parte incendiada y la inmediata construcción de la nueva Facultad de Ciencias ${ }^{19}$. Por entonces, los proyectos de las Facultades de Ciencias y Medicina se separan.

En relación a la Facultad de Medicina, el proyecto formulado por José Luis Oriol será ratificado por Real Decreto de 29 de septiembre de 1928, iniciándose las obras por replanteo un año después. A partir del incendio de la Universidad se hizo cargo de las obras del nuevo edificio el arquitecto Fungairiño. Algo más tarde, la reforma del proyecto primitivo de la Facultad de Medicina, con Alfonso Fungairiño ahora como responsable de las obras, será aprobada por Decreto el 31 de agosto de 1934. Un año después estaba prácticamente terminada, llegando incluso a pensarse que podría entrar en funcionamiento en el curso 1936-37. La guerra lo impidió y el edificio pasó a utilizarse como Hospital Militar.

Por otro lado, la llegada de Juan Peset Aleixandre al rectorado de la Universidad de Valencia se sitúa en la órbita de rectores republicanos. La valía excepcional de Peset contribuyó de manera notable a la modernización de la Universidad de aquellos años. En cuanto a infraestructuras, Peset encargó a su hermano, el arquitecto Mariano Peset Aleixandre, las obras de la nueva Facultad de Ciencias, formulando el proyecto correspondiente cuyos planos firma en abril de 1933 (Jurado, 1987, t. 1, 4-5, 20-23). Antes, se había reunido con los profesores para establecer las necesidades programáticas del nuevo edificio. Las obras comenzaron el 29 de julio de 1935, paralizándose poco después, en julio de 1936, por la guerra. A partir de este momento se intentó evitar que el edificio fuera tomado por los sindicatos obreros y, a la vez, que no se perdiera o deteriorase la obra realizada ${ }^{20}$. Terminada la guerra, y con el gobierno franquista instalado en el poder, se detendrá, condenará y encarcelará al que fuera rector Juan Peset, que será vilmente fusilado en la localidad valenciana de Paterna el 24 de

18 El Mercantil Valenciano, 10 de marzo de 1932, 4.

19 AUV. Archivo General, Libro no 2518, f. 40r-41v. Aunque con algún error de transcripción, el acta fue publicada parcialmente por la profesora Ma Fernanda Mancebo (1994, 214).

${ }^{20}$ Información reflejada en el documento firmado por el constructor Rafael Gil Grávalos el 9 de junio de 1939, en el que solicita instrucciones para la continuación de las obras de la Facultad de Ciencias. AUV. Archivo General, caja 1176/2. 
mayo de 1941. Ante esta terrible pérdida, y ante la atrocidad cometida, su hermano Mariano permanecerá un año enfermo y retirado de casi toda actividad profesional. Tras este doloroso periodo, y a pesar del gran coste emocional que supuso para él la guerra, recupera cierta normalidad haciéndose cargo de las obras de la Facultad de Ciencias. El nuevo edificio será inaugurado finalmente el 7 de octubre de 1944. Esta construcción se encuentra entre lo mejor de la producción arquitectónica de Mariano Peset y es una de las más representativas de la Ciudad Universitaria valenciana. En la actualidad, y tras un periodo de tiempo en el que fue Facultad de Farmacia, sus instalaciones sirven como Rectorado y Servicios Centrales.

Un nuevo impulso en la construcción de la Ciudad Universitaria vino determinado por los edificios proyectados por Javier Goerlich para la Universitat de València (Benito, Sánchez y Llopis, 2014). En 1925 había sido nombrado arquitecto de construcciones civiles del Ministerio de Instrucción Pública y Bellas Artes de la provincia de Valencia, lo que en la práctica significaba hacerse cargo de los edificios universitarios, tanto de la sede histórica como de las nuevas construcciones que iban a ser proyectadas y construidas. A partir de este momento presentará los proyectos de la Residencia de Estudiantes, la Escuela de Altos Estudios Mercantiles, el Campo de Deportes y la Escuela de Magisterio. Entre éstos destacará la Residencia de Estudiantes de 1935. En la memoria descriptiva del proyecto, conservada en el Archivo General de la Administración ${ }^{21}$, firmada en agosto de ese mismo año, el arquitecto Goerlich dirá:

Se proyecta, para llenar la necesidad dicha, un edificio de seis plantas emplazado en una manzana del Paseo de Valencia al Mar, a continuación de los edificios que se están levantando para las Facultades de Ciencias y Medicina y que juntamente con el campo de deportes universitario, proyectado también en esta misma zona, ofrecerán una pequeña ciudad universitaria digna de la importancia de Valencia.

El estilo racionalista de esta construcción parece derivarse de las líneas modernas del Club Náutico, que habían firmado conjuntamente, como se ha dicho, Goerlich y Fungairiño en 1932. Sin embargo, la inminente y cruenta guerra fratricida, y la consecuente falta de partidas presupuestarias, postergaron los edificios universitarios, que serán nuevamente retomados una vez termine el conflicto. No obstante, el interés por tener una Ciudad Universitaria parecía trascender las difíciles circunstancias políticas. Incluso en diciembre de 1936, cuando la guerra ya había comenzado, tiene lugar una reunión entre el entonces alcalde, José Cano Coloma, de Izquierda Republicana, y el ministro de Hacienda Juan Negrín, en la que se abordó, como tema principal, la construcción de una Ciudad Universitaria a imagen de la de Madrid $^{22}$. No extraña la presencia del alcalde de la ciudad en estas reuniones, ya que la educación superior era asunto fundamental en el gobierno de la ciudad, aunque dependía en gran medida del Estado. Además, el municipio cedió gratuitamente los solares donde iban a ser levantados los edificios universitarios. En todo este proceso jugará, como hemos dicho, un papel determinante Javier Goerlich. Recordemos que como Arquitecto de Construcciones Civiles, impulsará la construcción de la Ciudad Universitaria, pero también, y como arquitecto mayor del Ayuntamiento de Valencia, será el responsable del devenir arquitectónico de la ciudad, y por extensión de la planificación de sus espacios, incluidos los del paseo de Valencia al Mar y su Ciudad Universitaria.

\footnotetext{
21 AGA. IDD (05) 014.002, caja 31/05344, exp. 13558-2.

22 La Vanguardia, 4 de diciembre de 1936, 4.
} 


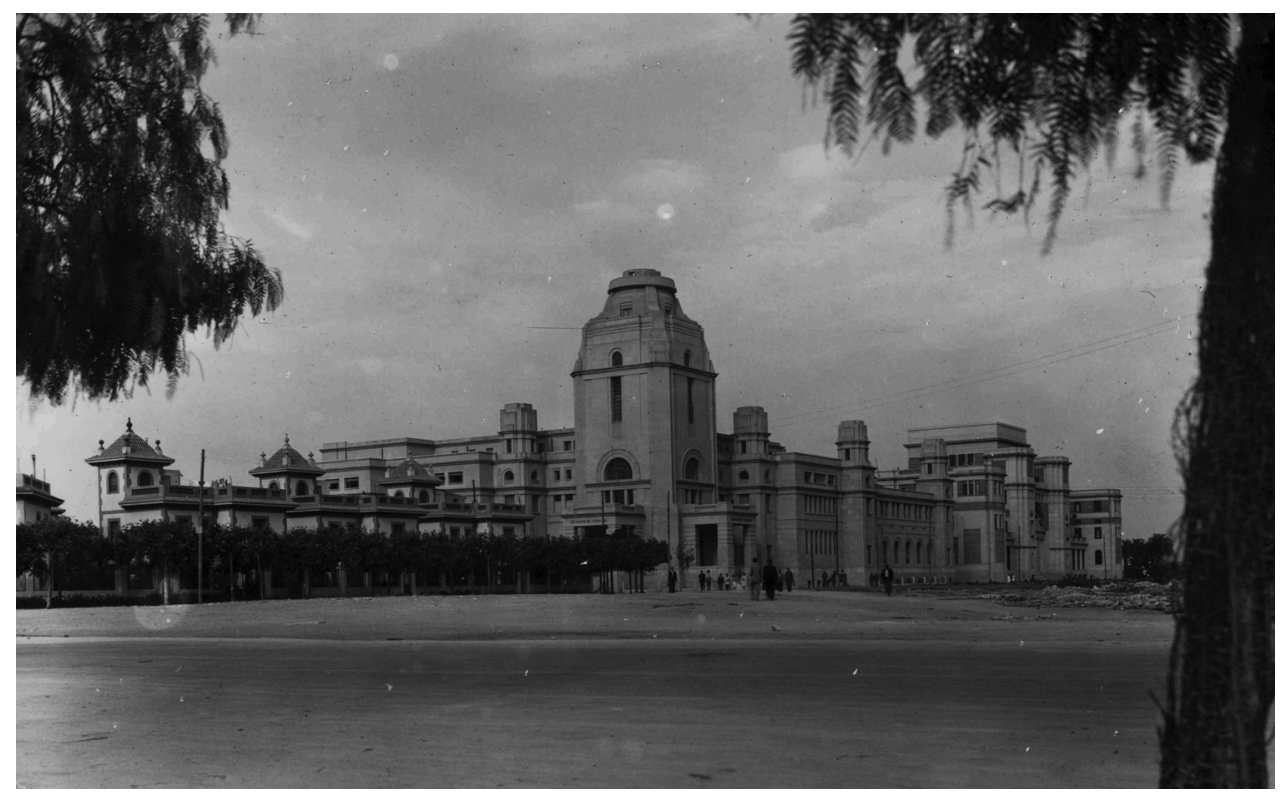

Chalets de los periodistas, la Facultad de Ciencias y la de Medicina. Archivo José Huguet.

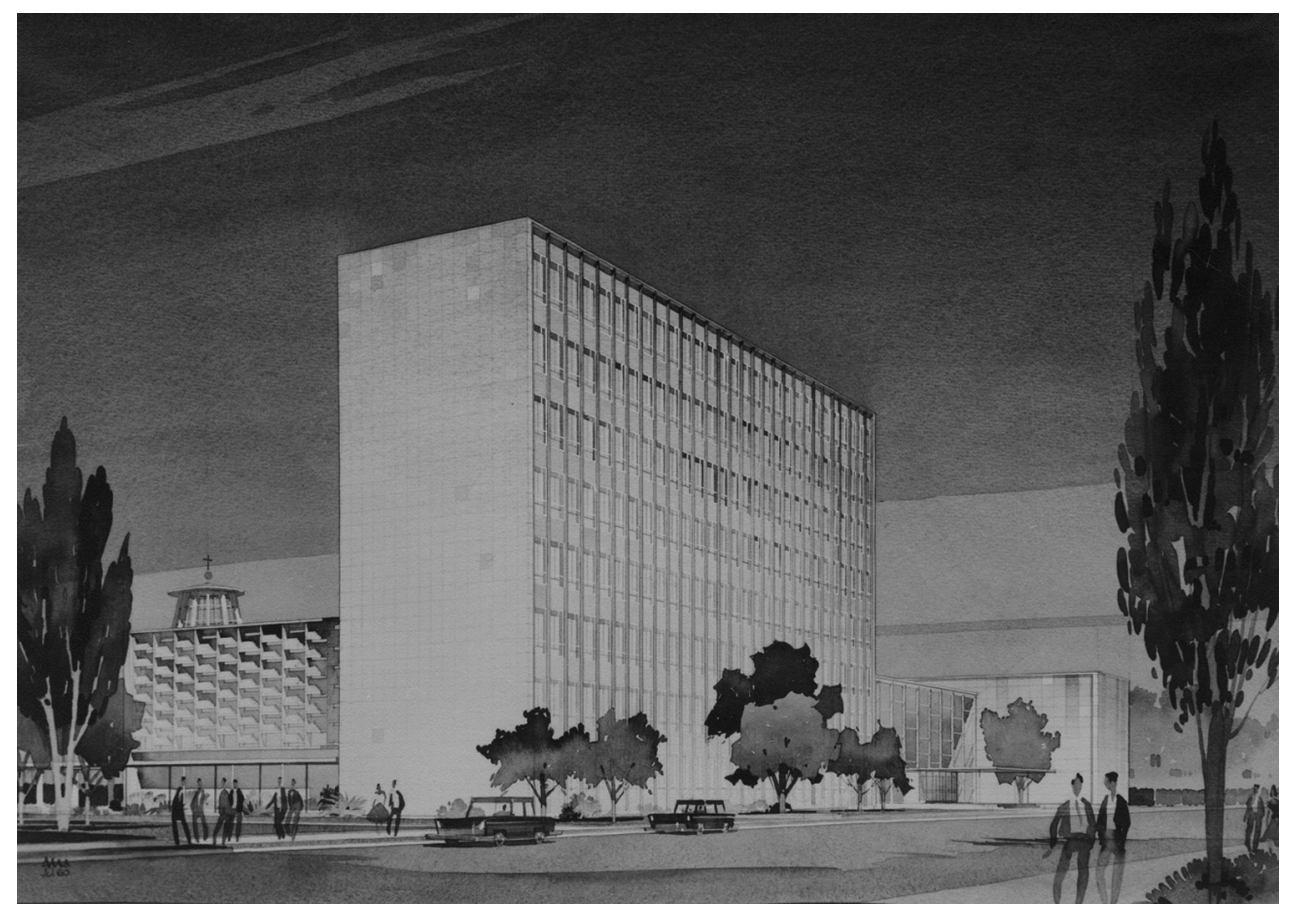

Antigua Facultad de Filosofía y Letras. Fernando Moreno Barberá, julio 1960. Archivo Área de Conservación de Patrimonio Cultural, UV. 
Asimismo, fue determinante en el proceso de construcción de la Ciudad Universitaria la perseverancia de este arquitecto, que llegó a presentar sus propuestas en numerosas ocasiones, hasta que finalmente fueron aprobadas. Javier Goerlich pudo contar además con el apoyo del rector de la Universidad Fernando Rodríguez-Fornos, ya que los proyectos habían sido redactados durante el primer mandato de este rector, entre julio de 1934 y febrero de 1936, dándose la circunstancia de que después de la guerra Rodríguez-Fornos será nombrado nuevamente rector de la Universidad, entre abril de 1941 y noviembre de 1951, periodo en el que las obras son finalmente aprobadas y ejecutadas, por lo menos en parte. En este sentido, también influirá la Ley de 29 de julio de 1943 sobre la ordenación de la Universidad española, especialmente en lo referente a los Colegios Mayores (aprobados con anterioridad). Por esta Ley: se restauran los Colegios Mayores en calidad de órganos obligatorios, de suerte que no podrá existir Universidad que no posea, como mínimo, un Colegio Mayor, a través del cual recibirán los escolares la educación universitaria en sus variados aspectos. En el artículo veintisiete de la Ley se hacía de nuevo hincapié en estos Colegios Mayores como órganos para el ejercicio de la labor educativa y formativa general que incumbe a la Universidad. Todos los escolares universitarios deberán pertenecer, como residentes o adscritos, a un Colegio Mayor y a través de él se cumplirán las funciones educativas que, con carácter obligatorio, deberán realizarse paralelamente a los estudios facultativos.

Cuando haya suficiente número de Colegios Mayores, será obligatoria la residencia de los escolares en alguno de ellos, salvo los que vivan con sus familiares o tutores. Lo cierto es que con esta fecha (1943) se vuelven a rotular los edificios universitarios de Javier Goerlich, es decir, se presentan de nuevo los proyectos antiguos añadiendo en su rotulación el nuevo año: la Residencia de Estudiantes, la Escuela de Altos Estudios Mercantiles y el Campo de Deportes ${ }^{23}$. Tiempo después, durante el segundo periodo rectoral de Rodríguez-Fornos, se terminarán también los edificios de las Facultades de Ciencias y Medicina. Más tarde, siendo rector José Corts Grau, Javier Goerlich levantará su último edificio universitario: la Escuela de Magisterio, según proyecto de 1955. Planteada inicialmente como Escuela Normal en la Ciudad Universitaria, no se construirá finalmente aquí. Desplazada a unos solares de Monteolivete, en la actual calle Alcalde Reig, 8, el edificio será inaugurado el 15 de octubre de 1964. Su estética, muy diferente a las iniciales construcciones racionalistas de su autor, se introduce en la arquitectura de inspiración madrileña muy en uso durante esos años.

A mediados del siglo XX el primer tramo del paseo de Valencia al Mar, parcialmente construido, contaba con los edificios de la Feria Muestrario, la Clínica Esperanza, las Facultades de Ciencias y Medicina, el Campo de Deportes, el Colegio Mayor Luis Vives, la Escuela de Comercio, el grupo de Casas Baratas de la Asociación de la Prensa Valenciana o "chalets de los periodistas", el grupo de viviendas unifamiliares de la Cooperativa de Casas Baratas Artes Gráficas y el posterior grupo de viviendas para la misma Cooperativa, junto con algunos solares vacíos. Fue característica de este espacio universitario la convivencia

23 Las acuarelas a color originales, propiedad de Carlos Viñes Goerlich, fueron expuestas, por primera vez, en la exposición La ciutat que habitem: arquitectura i espai urbà a València, 1939-1957; comisariada por David Sánchez Muñoz, tuvo lugar en el Museu d'Història de València, entre el 19 de julio de 2013 y el 2 de marzo de 2014. 
de tipologías bien diferentes y la construcción, en años posteriores, de viviendas residenciales que convivirán con estas arquitecturas universitarias. Por venir estaban los proyectos de Fernando Moreno Barberá. Los edificios de este último arquitecto son también parte fundamental del patrimonio arquitectónico de la Universitat de València y constituyen además un ejemplo magnífico y singular de la mejor arquitectura realizada en Valencia a lo largo del siglo XX.

Fernando Moreno Barberá (Blat, 2006a-b) ${ }^{24}$ forma parte de los arquitectos que introducen en Valencia un nuevo Movimiento Moderno. Se trata de una generación de profesionales, licenciados después de guerra, más abiertos a las tendencias arquitectónicas europeas y americanas. Sin embargo, las limitaciones de la sede histórica de la Universidad, y los graves daños que ha sufrido por la Riada de 1957, condiciona la puesta en marcha de las nuevas construcciones universitarias. En este contexto, el arquitecto Moreno Barberá proyectará y construirá un conjunto magnífico de edificios en el Campus de Blasco Ibáñez: la Facultad de Derecho (actual de Filosofia i Ciències de l'Educació), la Escuela de Ingenieros Agrónomos (actual Facultat de Psicologia), los Laboratorios de la Facultad de Ciencias (hoy Facultat d'Infermeria i Podologia) y la Facultad de Filosofía y Letras (actual Facultat de Geografia i Història). Estos edificios constituyen una parte muy significativa de la Ciudad Universitaria, modernos en su estética, y cuidados hasta los más mínimos detalles. Este conjunto arquitectónico trasciende la singularidad de cada uno de los edificios para formar parte de una misma idea constructiva. Además, Moreno Barberá formuló en 1960 una propuesta no realizada para la continuación del paseo de Valencia al Mar. El ideario de las grandes vías europeas seguía presente en este proyecto singular (Pérez, 2014, 29-52).

Todos los edificios de la Ciudad Universitaria de paseo Valencia al Mar fueron inaugurados después de guerra con presencia de altos mandatarios del Régimen franquista. Así, el ministro de Educación José Ibáñez Martín, inauguró el 7 de octubre de 1944 la Facultad de Ciencias y, más tarde, el Campo de Deportes y la Facultad de Medicina, el 12 y 13 de diciembre de 1949 respectivamente. La inauguración más importante, si atendemos a la presencia institucional, fue la del Colegio Mayor Luis Vives, que contó con la presencia de Franco, el 9 de octubre de 1954. Algún tiempo después, el 3 de octubre de 1960, el ministro de Educación Jesús Rubio García-Mina inauguró el Hospital Clínico. Luego, su sucesor en el cargo, el ministro de Educación Manuel Lora Tamayo, inauguraría: la Facultad de Derecho (el 10 de octubre de 1963), el pabellón sur del Hospital Clínico (el 23 de mayo de 1965) y la Escuela de Ingenieros Agrónomos (el 5 de diciembre de 1966).

Muy poco tiempo después se proyectó el último de los edificios que iban a formar parte de esta Ciudad Universitaria. Se trataba de la Facultad de Economía (actual Facultat de Filologia, Traducció i Comunicació), cuyo proyecto inicial de 1969 fue obra del arquitecto Salvador Pascual Gimeno ${ }^{25}$, luego reformado en 1971 por Juan Antonio Hoyos Viejobueno, por entonces arquitecto jefe de la Unidad Técnica de la Universitat de València y director de las obras del edificio. Deudor de los edificios para este campus de Moreno Barberá, no llega sin embargo a la eficacia compositiva de aquellos, siendo una obra más convencional y anodina.

${ }^{24}$ Sobre Moreno Barberá se han escrito ya algunos textos de referencia. Sin embargo, algunos errores en la datación de los edificios que realiza para la Universitat de València se han mantenido y reproducido en las diferentes aportaciones bibliográficas, por lo que, lejos de agotarse el tema, cabe esperar todavía la llegada de nuevos estudios que pongan de manifiesto el interés y alcance de este sobresaliente arquitecto.

25 Información del proyecto facilitada por el Archivo General de la Administración (AGA). 


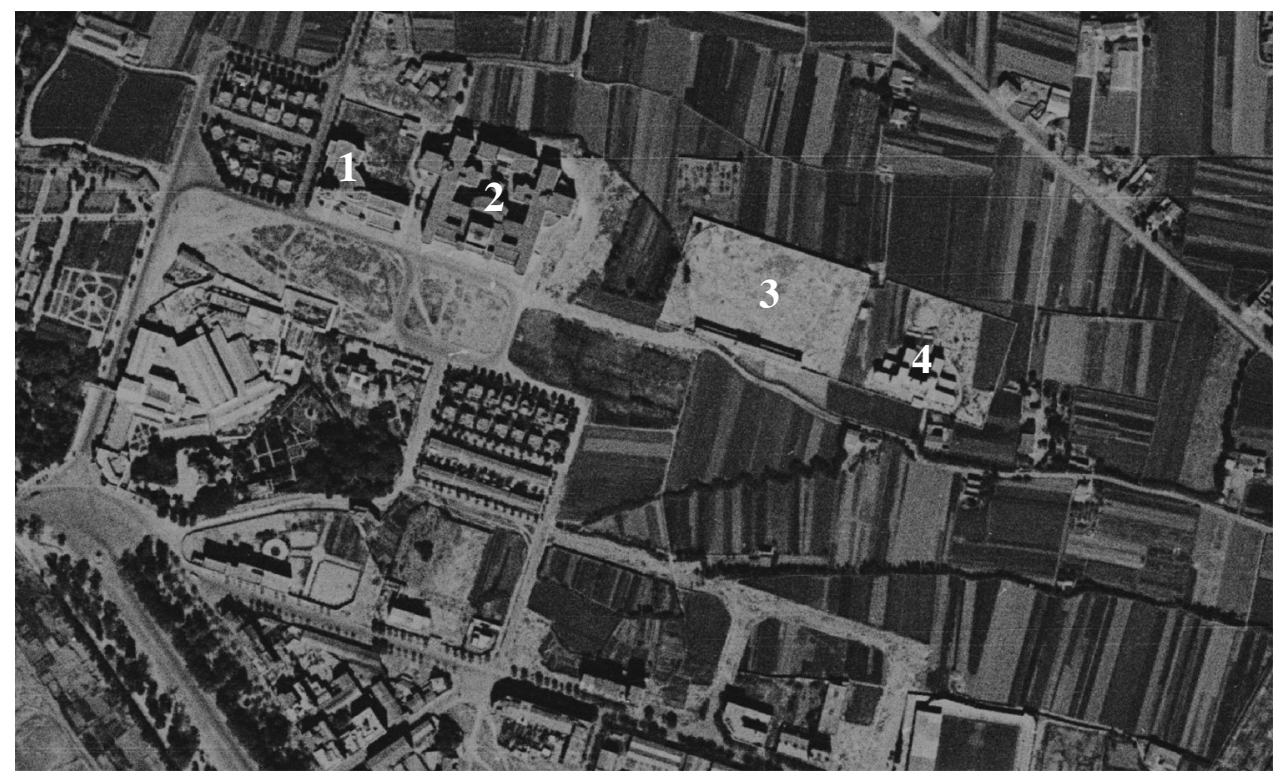

Ciudad Universitaria de Valencia en 1945. Vuelo americano, serie A (1945-1946). Centro Nacional de Información Geográfica.

1. Facultad de Ciencias.

2. Facultad de Medicina.

3. Campo de Deportes.

4. Colegio Mayor Luis Vives. 


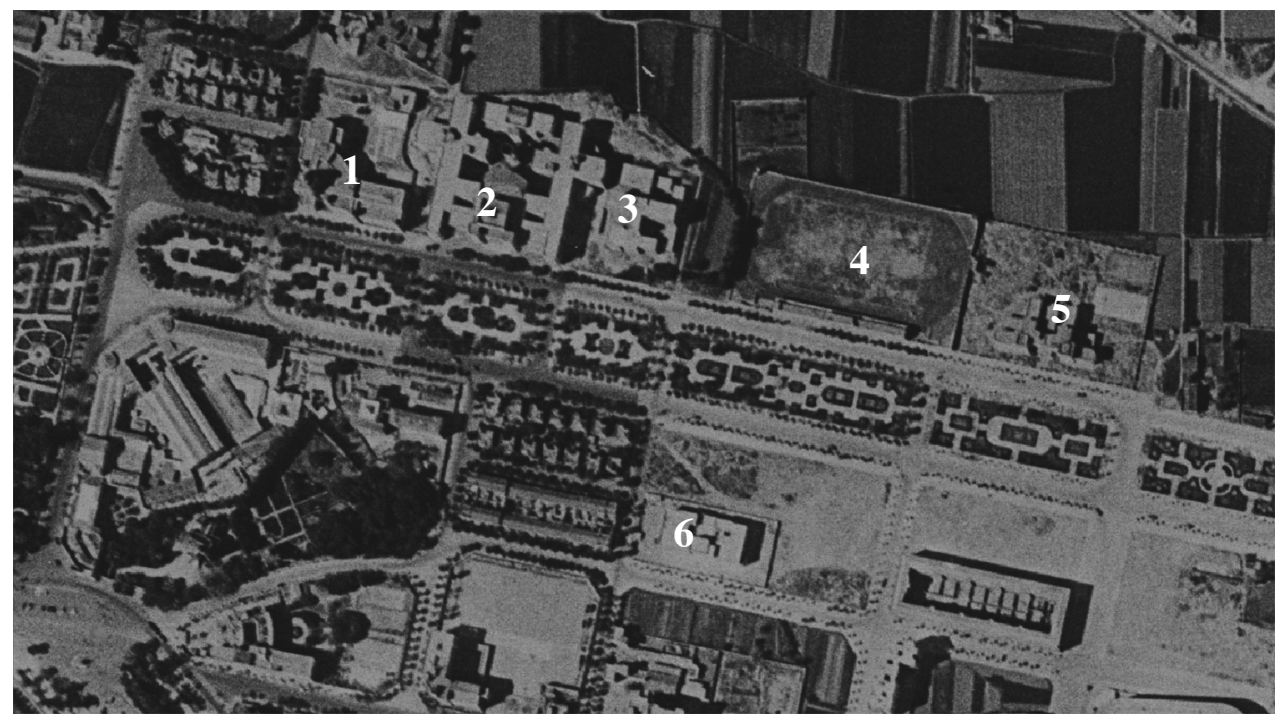

Ciudad Universitaria de Valencia en 1956. Vuelo americano, serie B (1956-1957). Centro Nacional de Información Geográfica.

1. Facultad de Ciencias.

2. Facultad de Medicina.

3. Pabellón de Especialidades de la Facultad de Medicina.

4. Campo de Deportes.

5. Colegio Mayor Luis Vives.

6. Escuela de Comercio. 


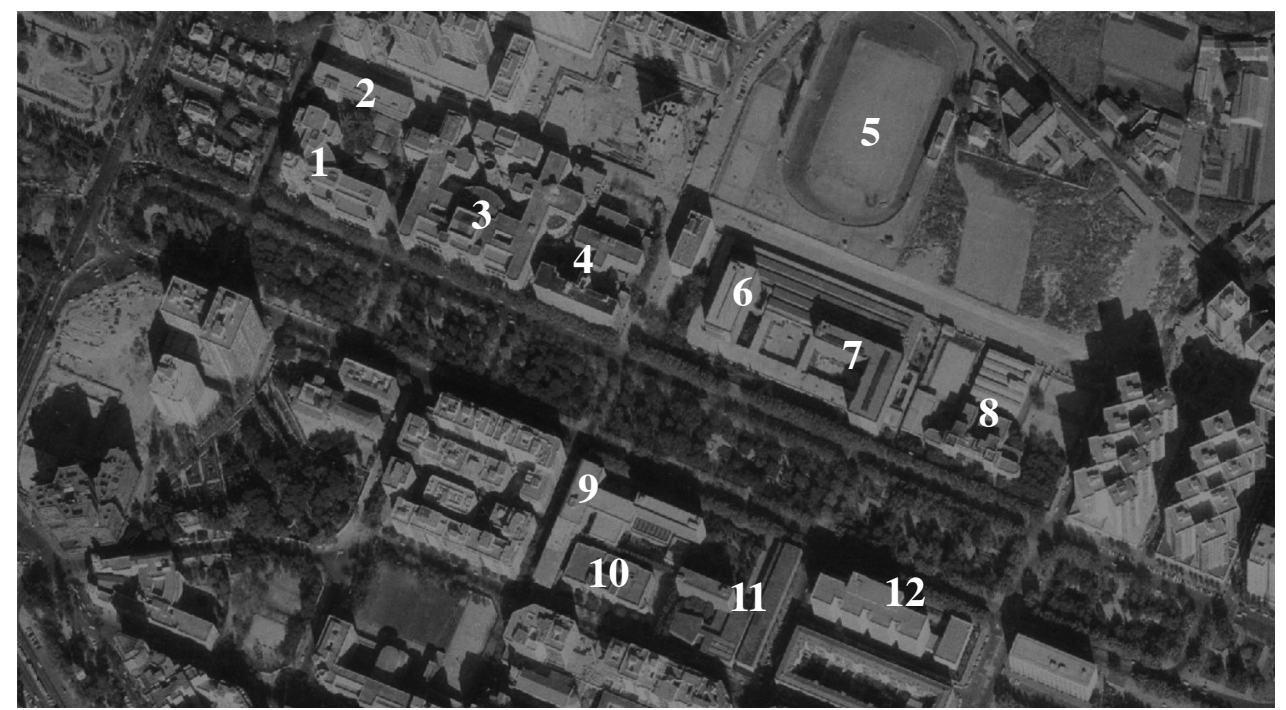

Ciudad Universitaria de Valencia en 1956. Vuelo Interministerial, 1973-1986. Centro Nacional de Información Geográfica.

1. Facultad de Ciencias.

2. Laboratorios de la Facultad de Ciencias.

3. Facultad de Medicina.

4. Hospital Clínico.

5. Campo de Deportes.

6. Escuela de Peritos Agrícolas.

7. Escuela de Ingenieros Agrónomos.

8. Colegio Mayor Luis Vives.

9. Facultad de Filosofía y Letras.

10. Escuela de Comercio.

11. Facultad de Derecho.

12. Facultad de Económicas. 
Edificios de la Ciudad Universitaria

\begin{tabular}{|c|c|c|c|}
\hline Edificio & Año proyecto original & $\begin{array}{c}\text { Fecha inauguración/ } \\
\text { terminación }\end{array}$ & Arquitecto \\
\hline $\begin{array}{l}\text { Facultad de Ciencias } \\
\text {-actual Rectorat- }\end{array}$ & $\begin{array}{l}1933 \\
\text {-sobre proyecto } \\
\text { anterior de José Luis } \\
\text { Oriol 1908- }\end{array}$ & 7 de octubre de 1944 & $\begin{array}{l}\text { Mariano Peset } \\
\text { Aleixandre }\end{array}$ \\
\hline $\begin{array}{l}\text { Facultad de Medicina } \\
\text {-actual Facultat de Medicina i } \\
\text { Odontologia- }\end{array}$ & $\begin{array}{l}\text { En } 1932 \text { se hace cargo } \\
\text { de las obras el ar- } \\
\text { quitecto Fungairiño } \\
\text {-sobre proyecto } \\
\text { anterior de José Luis } \\
\text { Oriol 1908- }\end{array}$ & $\begin{array}{l}13 \text { de diciembre de } \\
1949\end{array}$ & $\begin{array}{l}\text { Alfonso Fungairiño } \\
\text { Nebot }\end{array}$ \\
\hline $\begin{array}{l}\text { Escuela de Altos Estudios } \\
\text { Mercantiles -actual Biblioteca } \\
\text { d'Humanitats Joan Reglà- }\end{array}$ & 1935 & $\begin{array}{l}\text { Recibe los primeros es- } \\
\text { tudiantes el } 19 \text { de no- } \\
\text { viembre de } 1957\end{array}$ & Javier Goerlich Lleó \\
\hline $\begin{array}{l}\text { Residencia de Estudiantes } \\
\text {-CM Lluís Vives- (incluida en el } \\
\text { registro DOCOMOMO ibérico en } \\
2009 \text { ) }\end{array}$ & 1935 & 9 de octubre de 1954 & Javier Goerlich Lleó \\
\hline $\begin{array}{l}\text { Edificio de Especialidades de la } \\
\text { Facultad de Medicina, pabellón } \\
\text { central -actual Hospital Clínic } \\
\text { Universitari- }\end{array}$ & 1942 & 3 de octubre de 1960 & $\begin{array}{l}\text { Alfonso Fungairiño } \\
\text { Nebot }\end{array}$ \\
\hline -pabellón sur- & & 23 de mayo de 1965 & $\begin{array}{l}\text { Alfonso Fungairiño } \\
\text { Nebot }\end{array}$ \\
\hline $\begin{array}{l}\text { Antiguo Campo de Deportes } \\
\text {-Demolido- }\end{array}$ & 1941 aprox. & $\begin{array}{l}12 \text { de diciembre de } \\
1949\end{array}$ & Javier Goerlich Lleó \\
\hline $\begin{array}{l}\text { Antigua Escuela de Magisterio } \\
\text { (en Monteolivete) }\end{array}$ & 1955 & 15 de octubre de 1964 & Javier Goerlich Lleó \\
\hline $\begin{array}{l}\text { Facultad de Derecho -actual } \\
\text { Facultat de Filosofia i Ciències de } \\
\text { l'Educació- (incluida en el re- } \\
\text { gistro DOCOMOMO ibérico en } \\
\text { 2009) }\end{array}$ & 1959 & 10 de octubre de 1963 & $\begin{array}{l}\text { Fernando Moreno Bar- } \\
\text { berá }\end{array}$ \\
\hline $\begin{array}{l}\text { Laboratorios de la Facultad de } \\
\text { Ciencias -actual Facultat } \\
\text { d'Infermeria i Podologia- }\end{array}$ & 1959 & $\begin{array}{l}\text { Recepción definitiva } \\
1969\end{array}$ & $\begin{array}{l}\text { Fernando Moreno Bar- } \\
\text { berá }\end{array}$ \\
\hline $\begin{array}{l}\text { Escuela de Ingenieros Agrónomos } \\
\text {-actual Facultat de Psicologia- } \\
\text { (incluida en el registro } \\
\text { DOCOMOMO ibérico en 2009) } \\
\text { Escuela de Peritos Agrícolas }\end{array}$ & $\begin{array}{l}1960 \\
1968 \text { (reformado) }\end{array}$ & $\begin{array}{l}5 \text { de diciembre de } 1966 \\
\text { (edificio Agrónomos) } \\
\text { h. } 1968 \text { (edificio Peri- } \\
\text { tos) }\end{array}$ & $\begin{array}{l}\text { Fernando Moreno Bar- } \\
\text { berá } \\
\text { Cayetano Borso Gon- } \\
\text { zález }\end{array}$ \\
\hline $\begin{array}{l}\text { Facultad de Filosofía y Letras } \\
\text {-actual Facultat de Geografia i } \\
\text { Història- (incluida en el registro } \\
\text { DOCOMOMO ibérico en 2009) }\end{array}$ & 1960 & $\begin{array}{l}\text { El traslado a la nueva } \\
\text { Facultad tuvo lugar en } \\
\text { diciembre de } 1969\end{array}$ & $\begin{array}{l}\text { Fernando Moreno Bar- } \\
\text { berá }\end{array}$ \\
\hline $\begin{array}{l}\text { Facultad de Economía -actual } \\
\text { Facultat de Filologia, Traducció i } \\
\text { Comunicació- }\end{array}$ & $\begin{array}{l}1969 \\
\text { (proyecto original) } \\
1971 \text { (reformado) }\end{array}$ & $\begin{array}{l}\text { Recepción provisional } \\
\text { de las obras } 1972 \\
\text { Recepción definitiva } \\
1974\end{array}$ & $\begin{array}{l}\text { Salvador Pascual } \\
\text { Gimeno (original) } \\
\text { Juan Antonio Hoyos } \\
\text { Viejobueno (reformado) }\end{array}$ \\
\hline
\end{tabular}

Fuente: Elaboración propia. 
Como hemos visto, la Ciudad Universitaria de Valencia no tuvo un plano inicial global, pero consiguió finalmente cohesionar sus infraestructuras. La implicación de algunos de sus próceres propició - a lo largo del tiempo- su construcción, por encima de las dificultades y de algunos episodios tan dolorosos como la guerra (y sus consecuencias) y con sistemas políticos bien distintos. La perseverancia determinó pues el éxito del proyecto; y si bien aparecieron en el camino algunos problemas, mientras en ocasiones se demoraban e incluso paralizaban las obras, lo cierto es que se persiguió -durante décadas y con decisión- la consecución de un espacio universitario propio, al modo de los más modernos campus americanos, y con la Ciudad Universitaria de Madrid como referente más próximo, adaptado, eso sí, a las limitaciones y circunstancias de nuestro ámbito local.

Más tarde, la Universitat de València necesitó nuevos espacios. Para entonces, la Ciudad Universitaria ya se había consolidado como campus de Blasco Ibáñez. Luego fueron levantados -en este mismo lugar- algunos edificios más, principalmente como complemento y mejora -los llamados aularios-, pero lo fundamental ya estaba construido.

\section{BIBLIOGRAFÍA}

ALMELA Y VIVES, Francisco (1932): “Del ayer al mañana”, Blanco y Negro, 2156.

BENITO GOERLICH, Daniel; SÁNCHEZ MUÑOZ, David; LLOPIS ALONSO, Amando (2014): Javier Goerlich Lleó. Arquitecto valenciano (1886-1914-1972), Valencia, Ayuntamiento de Valencia-Pentagraf, $331 \mathrm{p}$.

BLAT PIZARRO, Juan (2006a): Fernando Moreno Barberá. Modernidad y arquitectura, Barcelona, Fundación Caja de Arquitectos, 271 p.

BLAT PIZARRO, Juan, editor (2006b): Fernando Moreno Barberá. Arquitecto, Valencia, ICAROCOACV, $171 \mathrm{p}$.

BOIRA MAIQUES, Josep Vicent (2000): "Els orígens del Passeig de València al Mar: el projecte de Manuel Sorní de 1865", Cuadernos de Geografía, 67-68, 191-207.

CAMPOS CALVO-SOTELO, Pablo (2000): La universidad en España: historia, urbanismo y arquitectura, Madrid, Ministerio de Fomento, $1037 \mathrm{p}$.

CAMPOS CALVO-SOTELO, Pablo (2004): 75 años de la Ciudad Universitaria de Madrid: memoria viva de un campus trascendental, Madrid, Editorial Complutense, $210 \mathrm{p}$.

CAMPOS CALVO-SOTELO, Pablo (2010): España-Campus de Excelencia Internacional, Madrid, Ministerio de Educación, 348 p.

CAPEL SÁEZ, Horacio (2005): La morfología de las ciudades. II, Aedes facere: técnica, cultura y clase social en la construcción de edificios, Barcelona, Ediciones del Serbal, 656 p.

CHÍAS NAVARRO, Pilar (1983): La Ciudad Universitaria de Madrid: planeamiento y realización (tesis doctoral en línea), Madrid, Universidad Politécnica de Madrid, 5 vols.

CHÍAS NAVARRO, Pilar (1986): La Ciudad Universitaria de Madrid: génesis y realización, Madrid, Editorial de la Universidad Complutense, $341 \mathrm{p}$.

GÓMEZ FERRER, Ramón (1915): "Nuevo edificio para las Facultades de Medicina y de Ciencias", La Medicina Valenciana, 174, 210-212.

INAUGURA (1944): "Se inaugura la Facultad de Ciencias en Valencia", Revista Nacional de Educación, 46, 72-90.

JUNTA (1947): La Ciudad Universitaria de Madrid, Madrid, Secretaría de la Junta de la Ciudad Universitaria.

JURADO JIMÉNEZ, Francisco (1987): La arquitectura de Mariano Peset Aleixandre [Obra monográfica dividida en tres tomos, disponible en línea. Colabora en su realización Fermín Badillo Julián]. 
LÓPEZ OTERO, Modesto (1941): "La arquitectura de la Ciudad Universitaria de Madrid", Revista Nacional de Educación, 4, 57-63.

LÓPEZ OTERO, Modesto (1943): "La arquitectura de la Ciudad Universitaria”, Revista Nacional de Educación, 34, 49-54.

LUQUE, Javier de (1931): Ciudad Universitaria de Madrid: notas críticas, Madrid, Imprenta Góngora, $95 \mathrm{p}$.

LLOPIS ALONSO, Amando-VTiM arqtes.; SÁNCHEZ MUÑOZ, David. "La ciudad que se encontró Javier Goerlich. A propósito de algunos proyectos sobre Valencia y su Reforma interior (1855-1925)", en: València 1808-2015: La història continua... Valencia, Ed. Balandra, 2016, 81-116.

MANCEBO, Ma Fernanda (1994): La Universidad de Valencia. De la Monarquía a la República (1919-1939), Valencia, Universitat de València, 429 p.

MARZAL RODRÍGUEZ, Pascual (2009): Una historia sin justicia. Cátedra, política y magistratura en la vida de Mariano Gómez, Valencia, Universitat de València, 321 p.

NUEVA (1949): "Nueva Facultad de Medicina en Valencia”, Revista Nacional de Educación, 91, 69-72.

ORIOL URIGÜEN, José Luis (1913): La Construcción Moderna, números: 9 (15 de mayo de 1913, 133-140), 10 (30 de mayo de 1913, 145-151), 11 (15 de junio de 1913, 163-167), 12 (30 de junio de 1913, 178-182), 13 (15 de julio de 1913, 201-206), 14 (30 de julio de 1913, 217-222), 15 (15 de agosto de 1913, 235-240), 17 (15 de septiembre de 1913, 270-272), 19 (15 de octubre de 1913, 299-302).

PÉREZ IGUALADA, Javier (2014): "Ecos del norte: la manzana híbrida en el proyecto para la Avenida de Valencia al Mar de Fernando Moreno Barberá (1959-60)", ACE: Architecture, City and Environment, 26, 29-52.

ROSELLÓ, Vicenç M.; BOIRA, Josep V (2000): "La universidad y la expansión urbana”, en Albiñana, S. (Ed.), Cinc segles $i$ un dia, Valencia, Universitat de València, 155-170.

RUIZ RODRIGO, Cándido (1993): Política y educación en la II República (Valencia, 1931-1936), Valencia, Universitat de València, $229 \mathrm{p}$.

SÁNCHEZ I SANTIRÓ, Ernest; REVERT I ROLDÁN, Ximo (1990): "Una arquitectura per a la ciència. La Facultat de Ciències de la Universitat de València (1909-1944)", Afers. Fulls de recerca i pensament, 10, 455-474.

SÁNCHEZ MUÑOZ, David (2013): "La avenida del Oeste de Valencia. Historia de un proyecto inacabado", Ars Longa, 22, 229-244.

SÁNCHEZ MUÑOZ, David (2014a): "Restos de un naufragio: el Colegio Mayor Luis Vives y la Ciudad Universitaria de Valencia”, en Benito Goerlich, D. (Ed.), La piel de los edificios, Valencia, Universitat de València, 101-114.

SÁNCHEZ MUÑOZ, David (2014b): "Conociendo a Goerlich”, en Benito, D., Sánchez, D., Llopis, A., Javier Goerlich Lleó. Arquitecto valenciano (1886-1914-1972), Valencia, Ayuntamiento de Valencia-Pentagraf, 77-105.

SÁNCHEZ MUÑOZ, David (Ed.) (2016): La Residencia de Estudiantes y la Ciudad Universitaria de Valencia: el Colegio Mayor Luis Vives, Valencia, Alfons el Magnànim.

VASILEVA IVANOVA, Aneta (Coord.) (2016): Fernando Moreno Barberá. Un arquitecto para la universidad, Valencia, Universitat de València, $121 \mathrm{p}$. 